RAE-IC, Revista de la Asociación Española de Investigación de la Comunicación vol. 8, núm. 16 (2021), 399-424 ISSN 2341-2690

Recibido el 22 de febrero de 2021 DOI: https://doi.org/10.24137/raeic.8.16.18 Aceptado el 9 de septiembre de 2021

\title{
Producciones radiofónicas en Brasil: movimientos y protagonismo de las clases por radio durante la pandemia de la Covid-19
}

Radio productions in Brazil: movements and prominence of radio classes during the Covid-19 pandemic

Prata, Nair

Universidade Federal de Ouro Preto (UFOP)

nairprata@uol.com.br

Campelo, Wanir

Sociedade Brasileira de Estudos Interdisciplinares da Comunicação (INTERCOM) wanircampelo@gmail.com

Caldas Pessoa, Sônia Universidade Federal de Minas Gerais (UFMG) soniacaldaspessoa@gmail.com

Ceniceros Manjarrez, Lorena Ilia Universidade Federal de Ouro Preto (UFOP) lorena.ilia.cm@gmail.com 


\section{Forma de citar este artículo:}

Prata, N., Campelo, W., Caldas Pessoa, S. y Ceniceros Manjarrez, L. I. (2021). Producciones radiofónicas en Brasil: movimientos y protagonismo de las clases por radio durante la pandemia de la Covid-19. RAE-IC, Revista de la Asociación Española de Investigación de la Comunicación, 8(16), 399-424. https://doi.org/10.24137/raeic.8.16.18

\section{Resumen:}

Incluso en una sociedad conectada y multiplataforma, ante epidemias y grandes calamidades, la radio es (re)convocada al protagonismo dadas sus características de ser un dispositivo simple, barato y accesible. Ante el aislamiento social impuesto por el riesgo de contaminación por el coronavirus, muchos alumnos de Brasil se vieron imposibilitados de continuar sus estudios debido a la realización de clases virtuales y las dificultades de acceso a Internet. A partir de una investigación con metodología cualitativa y presentación descriptiva, este trabajo buscó entender los movimientos realizados por la programación radiofónica de varias ciudades brasileñas para este acercamiento con las comunidades afectadas, reforzando el papel de conectar a las personas y promover la interacción, intentando garantizar a la sociedad el derecho a la información. Por lo tanto, este trabajo describe una recopilación de iniciativas educativas con el objetivo de apuntar el esfuerzo permanente de la radio por abrigar los variados escenarios de comunicación. A partir del entendimiento de Kaplún (1978) para los programas educativos, recopilamos experiencias de producciones radiofónicas que fueron mediatizadas entre marzo y julio de 2020 en Brasil.

Palabras clave: radio, pandemia, clases por radio.

\section{Abstract:}

Even in a connected and multiplatform society, in face of epidemics and great calamities, radio recall to its prominence given its characteristics of being a simple, cheap, and accessible device. Faced with the social isolation imposed by the risk of contamination by the coronavirus, many students in Brazil were unable to continue their studies due to virtual classes and difficulties in accessing the Internet. Based on an investigation with 
qualitative methodology and descriptive presentation, this work sought to understand the movements made by the radio programming of several Brazilian cities for this approach with the affected communities, reinforcing the role of connecting people and promoting interaction, trying to guarantee to society the right to information. Therefore, this work describes a compilation of educational initiatives with the objective of pointing out the permanent effort of the radio to shelter the various communication scenarios. Based on the understanding of Kaplún (1978) of educational programs, we compile experiences of radio productions that happened between March and July 2020 in Brazil.

Keywords: radio, pandemic, classes by radio.

\section{SENDEROS PEDAGÓGICOS}

En octubre de 1937, en Chicago, EUA, un brote de poliomielitis asustaba a la población. La enfermedad, extremadamente peligrosa para los niños, llevaba a la muerte o a la parálisis de los infectados. En este escenario, las escuelas dejaron de funcionar ya que no era posible mantener las clases ante el grave riesgo de contaminación. Por ello, la administración de la ciudad decidió llevar las clases a las casas de los más de 300 mil alumnos a través de la radio, una tecnología relativamente nueva y poco probada en el campo educativo. De esta forma, seis emisoras de radio asumieron el desafío de transmitir las clases -WENR, WLS, WIND, WJJD, WCFL y WGN-que eran preparadas por los profesores y revisadas por comités específicos. Los periódicos impresos también participaron en este proyecto informando en las ediciones de cada mañana las clases que serían transmitidas en ese día. Los contenidos eran divididos durante la semana: los lunes, miércoles y viernes eran dedicados a los estudios sociales y ciencias; martes, jueves y sábado, reservados para el contenido de inglés y matemáticas (Hines, 2020).

La comunicación y la educación son experiencias interrelacionadas (Soares, 1999), sujetas a la intervención social (Citelli, 2000) y sus procesos de significado -y también 
son influenciados- en los procesos educativos de interpretación del mundo (Santaella, 2000).

La experiencia de Chicago muestra que el uso de la radio como herramienta educativa no es nuevo. Entre las tres funciones básicas de la radio, nombradas por Mario Kaplún (1978), se encuentra la educación, que comparte con la información y el entretenimiento los pilares que orientan las clasificaciones atribuidas a las categorías de programas radiofónicos, a saber: informativos, educativos-culturales y de entretenimiento. El autor defiende que la educación del individuo no se da solo en la infancia y en la adolescencia en las aulas, si no que ocurre de manera permanente, a lo largo de toda nuestra vida, en función de los estímulos y de las situaciones vividas por cada uno.

Kaplún (1978) habla sobre "la pedagogía del medio radiofónico" (p. 18) y conceptualiza la educación radiofónica en un sentido más amplio:

No solo las emisiones especializadas que imparten alfabetización y difusión de conocimientos elementales -cometidos cuya utilidad y necesidad no se cuestionan-, sino también todas aquellas que procuran la transmisión de valores, la promoción humana, el desarrollo integral del hombre y de la comunidad; las que se proponen elevar el nivel de conciencia, estimular la reflexión y convertir a cada hombre en agente activo de la transformación de su medio natural, económico y social (Kaplún, 1978, p. 22).

Según Kaplún (1978), la radio puede ser entendida como un instrumento de educación popular, pero explica que un programa educativo no tiene que ser aburrido como las medicinas de nuestra infancia, que para que hicieran efecto, debían tener sabor amargo y desagradable. Apunta las características de programas de radio como instrumento de educación:

1. Serán programas que tiendan a estimular un proceso en los oyentes, más que a inculcarles conocimientos o a perseguir resultados prácticos inmediatos;

2. Ayudarán al oyente a tomar conciencia de la realidad que lo rodea, tanto física como social; se integrarán en esa realidad, partirán de su propia problemática concreta, de su situación vivencial; 
3. Les facilitará los elementos para comprender y problematizar esa realidad. Serán programas problematizadores;

4. Estimularán la inteligencia; ejercitarán el raciocinio, harán pensar, llevarán a una reflexión;

5. Se identificarán con las necesidades y los intereses de la comunidad popular a la que se dirigen. Procurarán que ella descubra esas necesidades e intereses;

6. Estimularán el diálogo y la participación. En algunos casos tomarán la forma de programas directamente participativos; $y$, en todo caso, "crearán las condiciones pedagógicas para el desarrollo de una práctica de participación". Acentuarán los valores comunitarios y solidarios, llevarán a la unión y a la cooperación;

7. Estimularán el desarrollo de la conciencia crítica y la toma de decisiones autónoma, madura y responsable;

8. Colaborarán a que el oyente tome conciencia de la propia dignidad, del propio valor como persona (Kaplún, 1978, p.36-37).

En el aislamiento social causado por la pandemia de la Covid-19, muchos países, incluyendo Brasil, enfrentaron el problema de ver sus escuelas cerradas y a miles de alumnos sin clases. En este trabajo, partimos de Kaplún (1978) para intentar entender algunas experiencias de producciones radiofónicas que tienen como base las clases por radio $\mathrm{u}$ otras iniciativas que buscan trasladar el aula para las ondas hertzianas o ambientes digitales, y que fueron mediatizadas por medio de registros de órganos gubernamentales o de profesores y profesionales de la educación envueltos en estas iniciativas.

A partir de una investigación con metodología cualitativa y presentación descriptiva, este trabajo detalla una recopilación de iniciativas educativas, con objetivo de señalar el espacio permanente de la radio para albergar los distintos escenarios comunicativos. Con base en la comprensión de Kaplún (1978) para los programas educativos, recopilamos experiencias de producciones radiofónicas realizadas en Brasil al inicio de la pandemia. 
Para la construcción de la muestra, buscamos como faro el primer semestre de estudios en tiempos normales en Brasil, el cual contempla los meses de marzo a julio. Para ello, realizamos una investigación en Internet a partir de un marco temporal que incluye este mismo periodo, pero del año 2020, siendo marzo el mes que da inicio el aislamiento social en la mayoría de las ciudades brasileñas con el decreto del gobierno de suspensión de clases presenciales, y julio el mes que da apertura a las vacaciones escolares en tiempos de normalidad, cuando las clases son presenciales. Buscamos en los sitios web de noticias, las experiencias de clases por radio y obtuvimos una muestra de 12 casos que fueron mediatizados y que muestran el esfuerzo permanente de la radio al albergar los distintos escenarios comunicativos.

Como bien sabemos, la pandemia ha afectado al mundo de forma brutal, y América Latina ha sentido particularmente los efectos del coronavirus en varios aspectos. En los primeros momentos de pandemia, en varias áreas del conocimiento se crearon comités de gerenciamiento de la Covid-19 en busca de estrategias para la gestión del aislamiento social y el control de la enfermedad mientras la vacuna aún no había sido creada. La educación se vio ampliamente afectada, con millones de alumnos fuera de las aulas, teniendo que estudiar en casa y sin acceso a dispositivos tecnológicos e Internet. El director regional de la Unicef para América Latina y el Caribe, Bernt Aasen, afirma que "para quienes no tienen una computadora, internet o incluso un lugar para estudiar, aprender en casa se ha convertido en un gran desafío". Para la Unicef, América Latina enfrenta a una crisis educativa, con el cierre de escuelas más amplio de cualquier región del mundo (Unicef, 2020). "Mientras que muchos estudiantes de los países más prósperos han regresado a las aulas, 100 millones de niños de América Latina siguen estudiando total o parcialmente a distancia" (Turkewitz, 2021). Según estimaciones del Banco Mundial, publicadas en el periódico:

es posible que millones de niños en América Latina ya hayan abandonado el sistema escolar. En México, 1,8 millones de niños y jóvenes no retomaron sus estudios este año, lo que equivale a cerca del cinco por ciento de la población en edad escolar, según el Instituto Nacional de Estadística y Geografía del país. 
Se calcula que Ecuador perdió 90.000 alumnos de primaria y secundaria. Perú dice que ahora hay 170.000 menos. Y a las autoridades les preocupa que las pérdidas reales sean mucho mayores porque innumerables niños siguen técnicamente matriculados, pero tienen dificultades para continuar sus estudios. Más de cinco millones de niños en Brasil no han tenido acceso a la educación durante la pandemia, un nivel no visto en más de 20 años, dice Unicef (The New York Times, 2021).

En Brasil, en este escenario educativo lleno de desafíos, teniendo la pandemia como elemento provocador, fue necesario buscar nuevos métodos y dinámicas didácticopedagógicas o redescubrir el potencial de estrategias que fueron probadas hace años y que funcionaron bien durante algún tiempo. La radio fue una de las posibilidades encontradas.

Veremos a continuación cómo la radio y la educación se entrelazan en la sociedad brasileña.

\section{RADIO Y EDUCACIÓN}

En Brasil, el uso de la radio como herramienta pedagógica aplicada en el proceso de aprendizaje de niños y jóvenes, no trae novedades. Esta comenzó sirviendo a la educación históricamente hace casi un siglo. Fue el médico y profesor Roquette-Pinto quien más tarde llegó a convertirse en el líder de la radiodifusión en el país, con la idea de hacerse de la primera emisora de radio fundada en Brasil, el 20 de abril de 1923, una estación educativa con fines científicos y culturales. Este potencial pedagógico de la radio fue posteriormente reafirmado por muchos educadores, entre ellos, el brasileño Paulo Freire, uno de los pensadores más notables de la pedagogía mundial. Es notorio un discurso de Roquette-Pinto, publicado por Albertin (2016), cuando destaca la importancia de la radio en el proceso educativo:

Nosotros, que vimos el amanecer de la radio, sentimos lo que deberían haber sentido algunos de los que lograron poseer y leer los primeros libros. La radio es la escuela de los que no tienen escuela, es el periódico de los que no saben leer, es el maestro de los que no pueden ir a la escuela, es la diversión gratuita del pobre, es el animador de nuevas esperanzas, el consolador de los enfermos y el guía de los solitarios, siempre que lo 
hagan con espíritu altruista y elevado. Por la cultura de los que viven en nuestra tierra, por el progreso de Brasil (Albertin, 2016, p. 28).

La Rádio Sociedade de Rio de Janeiro nació anclada en dos pilares establecidos por Roquette-Pinto. Consciente del profundo valor de la información y de la cultura, él siempre creyó que la radio debía servir para difundir la educación en el país. Los intentos de una programación educativa y accesible para la mayoría de la población no alcanzaron sus objetivos debido a las condiciones socioculturales que privilegiaban un modo de vida vinculada a la élite brasileña. Roquette-Pinto creía que la radio ayudaría a resolver los problemas educativos del país debido al contacto directo entre la emisora y el oyente, siempre que se creara una didáctica especial para la enseñanza radiofónica (Campelo, 2001).

Las primeras experiencias educativas por la radio se remontan a la década de 1930, cuando en Rio de Janeiro fue implantada la Rádio-Escola Municipal, la cual transmitió por primera vez el 31 de diciembre de 1933. Con clases basadas en preguntas y respuestas, la estación enviaba lecciones a través del Correo a los alumnos registrados, quienes devolvían las preguntas contestadas a la radio. En la década de 1940, el programa Universidade do Ar, transmitido por la Rádio Nacional en Rio de Janeiro, estaba dirigido a los profesores de nivel medio superior con contenido específico para el desempeño en clase. También en São Paulo se vivió la experiencia del programa Universidade do Ar a finales de los años 40 con la transmisión por más de una decena de emisoras (Pimentel, 2009).

A principios de la década de 1960, un proyecto denominado Sirena (Sistema RádioEducativo Nacional) producía, grababa y distribuía cursos básicos que eran transmitidos por emisoras de radio. Uno de los proyectos de radio educativo de mayor destaque fue el MEB (Movimento de Educação de Base), creado en 1963 y vinculado a la Iglesia Católica. El proyecto estaba dirigido para el trabajador rural y actuó fuertemente en la concientización social de los participantes de los cursos. Con las clases transmitidas en vivo, el MEB también produjo folletos con contenido sobre concientización social y política. Otra experiencia destacada, fue el famoso Projeto Minerva, un sistema oficial 
de enseñanza por la radio en los años 70, dirigido a adultos que no podían asistir a clases en cursos regulares. El programa era transmitido obligatoriamente por todas las radios del país, inmediatamente después del programa gubernamental $A$ Hora do Brasil (Pimentel, 2009).

Han pasado cerca de cien años desde las ideas de Roquette-Pinto sobre "la radio es la escuela de los que no tienen escuela, es el periódico de los que no saben leer, es el maestro de los que no pueden ir a la escuela" (Albertin, 2016) y la escuela se va materializando de nuevo, gradualmente, a través de las ondas de radio. En el contexto de pandemia, ya no se trata de programas educativos producidos por la propia emisora, sino de clases elaboradas y presentadas por profesionales de la educación de algunas regiones del país, en donde el Internet no llega para todos. La radio, sin embargo, puede llegar a los estudiantes y familiares de manera más rápida, simple y eficaz, además de ser un dispositivo de fácil conexión entre escuelas y estudiantes.

La radio es escuchada por el $83 \%$ de los brasileños, en un promedio aproximado de cuatro horas y media por día. Entre los oyentes, el $84 \%$ prefieren escuchar por el aparato de radio, el $20 \%$ por el celular y el $3 \%$ por la computadora. A los brasileños $-70 \%$ de ellos - les gusta escuchar la radio en casa, al $23 \%$ en el coche y al $8 \%$ mientras se desplazan de un lugar a otro (Kantar Ibope Media, 2019). Ya la inclusión digital total aún no es una realidad en Brasil. En el escenario pre-pandemia, 12,646 millones de familias brasileñas aún no tenían acceso a Internet en casa. Cerca de 39,8 millones de brasileños de 10 años o más de edad no utilizaban la red, y todavía había 34,9 millones de personas en este rango de edad que no tenían teléfonos celulares (IBGE, 2019). Ante esto, es fácil entender por qué la radio fue una alternativa posible en este escenario en donde el acceso a las ondas hertzianas es más viable que la Internet.

\section{EL ESCENARIO INIMAGINABLE DE UNA PANDEMIA}

El año 2020 apenas había comenzado. Era febrero y Brasil se preparaba para otro Carnaval, su fiesta más popular. Al otro lado del mundo, a casi 18 mil kilómetros del país, 34 brasileños que vivían en la ciudad china de Wuhan, epicentro del nuevo coronavirus, hacían sus maletas para regresar a Brasil. Los repatriados embarcaron el 7 de febrero en 
dos aeronaves de la Fuerza Aérea Brasileña y el día nueve, luego de cuatro escalas, arribaron a Anápolis, Goiás, para cumplir con la cuarentena antes de regresar a sus hogares (PORTAL G1a, 2020). Dos semanas después, Japón, Camboya, Singapur, Corea, Tailandia, Vietnam, Alemania, Italia, Emiratos Árabes Unidos y otros países, ya registraban también sus primeros casos de Covid-19. El Miércoles de Ceniza, 26 de febrero, mientras los juerguistas recogían sus disfraces, el ministro de Salud, Luiz Henrique Mandetta, confirmaba el primer caso de la enfermedad en Brasil. A partir de entonces, las cifras empezaron a crecer exponencialmente. Los Estados comenzaron a decretar emergencia. Medidas preventivas empezaron a ser adoptadas de norte a sur.

Desde entonces, el número de víctimas de la enfermedad creció de forma alarmante, mientras las manos permanecen exudando el olor a alcohol y los rostros aún se muestran cubiertos por los cubrebocas. Sigue siendo recomendable respetar el distanciamiento y mantener la práctica de las recientes etiquetas de convivencia social, aceptando la necesidad de aislamiento, guardando, para un futuro incierto, besos y abrazos reprimidos. Llenos de inseguridad, los brasileños viven una nueva realidad, rodeados de cuidado y mucho miedo, intentando aceptar un extraño escenario impuesto llamado "la nueva normalidad".

En este escenario, la radio sigue presente en situaciones de emergencia en relación con las comunidades afectadas. Según la Asociación Brasileña de Emisoras de Radio y Televisión (Abert, 2019), desde su invención, la radio siempre ha estado al servicio de la integración social: "en Estados Unidos, las alertas sobre tormentas de nieve ya han salvado miles de vidas. El virus del Ébola fue contenido en África gracias a una eficiente red de radiodifusión. En Brasil, otros ejemplos que ayudaron a salvar vidas: en Santa Catarina, dos radios se turnaron al aire para ayudar a la población local, aislada por las inundaciones, a encontrar refugio". En Chile, que concentra el $30 \%$ de la energía sísmica mundial, la radio jugó un papel fundamental mientras que otros medios no pudieron llegar a la población en el momento de los choques sísmicos. Así, la Oficina Nacional de Emergencia de Chile (ONEMI) fabricó un receptor de radio solar que forma parte del kit de emergencia de las familias chilenas. El receptor de radio recibe transmisiones de FM y está hecho de cartón, el cual, puede ser doblado y guardado, de fácil distribución entre 
la población y con energía garantizada por el papel solar con el que está fabricado (Martínez-Costa y Prata, 2017).

En Brasil, en tiempos de pandemia, no fue necesario inventar nuevos equipos para la recepción radiofónica, lo que estamos escuchando, son posibilidades de llevar pedagógicamente a través de la radio, el aprendizaje que no se puede tener en las aulas de manera presencial.

\section{EL AULA EN EL DIAL}

Mientras la mayoría de las escuelas públicas y privadas brasileñas recurrieron a aplicaciones y herramientas en ambientes digitales para mantener a los alumnos en una nueva modalidad de enseñanza, la remota, algunos lugares necesitaron buscar la radio, retomando una práctica ya conocida, pero eficaz, para viabilizar el acceso de muchos estudiantes. Entendemos esta retomada como "educación radiofónica", pensada por Kaplún (1978), en un sentido más amplio, capaz de afrontar la complejidad de los impactos en el escenario educativo provocados por la Covid-19 y por la suspensión de las clases presenciales:

(...) no solo las emisiones especializadas destinadas a la alfabetización y difusión de conocimientos básicos - cuya utilidad y necesidad no se cuestionan - sino también aquellas que buscan la transmisión de valores, la promoción humana, el desarrollo integral del hombre y de la comunidad; aquellas que proponen elevar el nivel de conciencia, estimular la reflexión y convertir a cada hombre en un agente activo en la transformación de su entorno natural, económico y social (Kaplún, 1978, p.21).

Si por un lado no tenemos elementos para evaluar en profundidad los impactos de las clases por radio, y comprender en detalle si efectivamente contribuyen a los aspectos de desarrollo; por otro lado, entendemos que es importante el registro de estas experiencias, realizadas aquí, a través de reportajes y posts publicados en ambientes digitales. Estas clases por radio son pistas de un momento particular de la sociedad, de la educación y de la radiodifusión en pro de la educación. 


\section{EXPERIMENTACIONES DE CLASES POR RADIO}

Para comprender la alianza entre la radio y el sistema educativo brasileño en un escenario de pandemia, recopilamos experiencias realizadas desde el norte al sur del país. Son experiencias mediatizadas, es decir, publicadas en periódicos y revistas como textos periodísticos. La recolección de datos se centró en estas publicaciones, con base en los datos reportados. Este artículo no pretende profundizar cada una de las experiencias, sino mostrar cómo las iniciativas educativas pueden enriquecerse ante una pandemia abrumadora, con la radio como protagonista. De las publicaciones encontramos 12 experiencias pedagógicas-radiofónicas, que aquí se presentan en orden cronológico, aunque algunas de ellas no tienen una fecha definida. Como la muestra se centra en el período comprendido entre marzo y julio de 2020, la investigación no puede indicar cuándo finalizaron los experimentos o si continúan desarrollándose. En algunos experimentos no fue posible informar la fecha de inicio, solo sabemos que se llevaron a cabo las actividades por radio.

La primera experiencia que nos gustaría mencionar se llevó a cabo justo al inicio de la pandemia en Brasil, cuando la gente comenzó a retirarse a sus hogares ante el aislamiento social impuesto por el gobierno. En el Estado de Maranhão, en la región Noreste de Brasil, desde el 30 de marzo de 2020 la Rádio Timbira transmite diariamente contenidos referentes a los componentes curriculares de primaria, secundaria y preparatoria. La iniciativa, adoptada por la Secretaría de Educación del Estado en función de los riesgos traídos por el coronavirus, han evitado el desplazamiento diario de miles de alumnos que, durante años, han caminado muchos kilómetros para llegar a sus escuelas. Ahora, no hay más distancia que recorrer. Incluso para aquellos que tienen acceso a Internet, la radio ha sido la opción preferida de muchos estudiantes. Según el profesor Elvis John, en una entrevista con Portal Amazônia (2020), el medio tiene un papel muy importante en este contexto y puede consolidarse como instrumento de aprendizaje, incluso con el fin de la suspensión de las clases presenciales. De lunes a viernes, de 16 a 18hrs, toda la programación de la emisora está dirigida al público estudiantil. Una vez emitidas, estas actividades pedagógicas se ponen a disposición en la TV y en plataformas virtuales como YouTube, redes sociales y streaming a través de 
portales gubernamentales, la Secretaría de Educación del Estado, Rádio Timbira y la Asamblea Legislativa, así como emisoras repetidoras del interior. La Rádio Timbira 1290 AM, fundada en 1941, es considerada la más antigua de Maranhão, también de origen estatal. Además del contenido institucional, tiene una tradición en la cobertura deportiva (Ribeiro y Praxedes, 2011).

El Estado de Ceará también encontró en la radio un camino posible para llevar a los alumnos de la Escuela Estatal Profesor Milton Façanha Abreu, en Mulungu, a 120 kilómetros de Fortaleza, el contenido escolar que no puede más ser dado presencialmente en las aulas, en función de la pandemia. Las actividades remotas, vía Internet, se iniciaron después de la paralización presencial, a final de marzo de 2020, pero después fue constatada la dificultad de más de 100 alumnos para acompañar el contenido, muchos de ellos de la zona rural y sin acceso a celulares y computadoras. La idea de utilizar la radio surgió, entonces, a partir de ahí, cuando se verificó que un tercio de los alumnos no estaban accediendo a Internet o entregando los trabajos online. Para vencer el aislamiento y las diferencias tecnológicas, se optó por el uso de la radio. La experiencia que se ha venido realizando desde entonces por la Rádio Comunitária Paz FM, ha contemplado alumnos de preparatoria sin acceso a Internet, garantizando que el contenido llegue igualmente para todos. Las clases tienen duración de una hora, son presentadas tres veces por semana por los profesores de la escuela y se dividen por áreas de conocimiento, como matemáticas, ciencias naturales, ciencias humanas, idiomas y artes. Las dudas relacionadas a los contenidos impartidos pueden ser llevadas a los profesores en horario agendado por medio de una llamada telefónica.

El profesor de idiomas Márcio Fernandes explica que prepara sus clases a partir de una lógica bien creativa para que todos puedan comprender el asunto (Diário do Nordeste, 2020). El afirma que, en ese periodo de crisis, el proyecto en la radio acabó abrazando a todos los alumnos del municipio, pues se trata de una gran reinvención porque la educación no puede parar. En sus clases, el usa música temática y lleva invitados para hablar sobre determinados asuntos, todo para que el mensaje llegue a los alumnos de la manera más clara posible. En el último año de escuela, a punto de hacer el examen para el acceso a la Universidad, Rhayane Gomes dos Santos cuenta que la pandemia 
complicó todo al principio. Sin embargo, con el paso del tiempo, ella reconoce que los estudiantes fueron adaptándose a sus clases remotas, ya sea por Internet o por la radio (Diário do Nordeste, 2020). La Rádio Paz 98.5 FM es una emisora ecléctica y está ubicada en el noroeste cearense.

En la primera semana de mayo de 2020, los alumnos de la red estatal de enseñanza de Goiás, Estado de la región central de Brasil, también se encontraron en las ondas de la radio la alternativa para seguir con los estudios en tiempos de pandemia. Las radios Brasil Central AM y FM comenzaron a transmitir clases en directo, elaboradas por la Secretaría de Estado de Educación. Las inserciones son hechas dos veces al día, de lunes a viernes. Por la mañana de 10 a 10:30, las clases son destinadas a los grupos de preparatoria. Ya por la tarde, entre las 15 y 15:30, el programa aborda contenido para los grupos de primaria y secundaria. Ese régimen especial de enseñanza no presencial, comprende en cada periodo de transmisión dos encuentros de dos componentes curriculares diferentes, que siguen el mismo cronograma de las clases y actividades publicados en el portal NetEscola, que se actualiza semanalmente. Alumnos de primaria y secundaria, sin acceso a Internet, también reciben semanalmente actividades impresas, que son producidas por la Secretaría de Estado de Educación y repasadas a las Coordinaciones Regionales de Educación. Depende de la Rádio Brasil Central - RBC transmitir las clases a los alumnos de primaria, secundaria y preparatoria (Secretaria de Educação, 2020).

La RBC AM 1270 fue fundada hace 70 años con una programación de fuerte atractivo popular, música, periodismo y deporte. Ya la RBC FM 90.1 se centra en la música y la información, con contenido periodístico, artístico y curiosidades (Campos y Caetano, 2011). Las clases son transmitidas en ambas emisoras.

En el extremo sur de Brasil, en Rio Grande do Sul, en una ciudad gaucha llamada Candelária, a 187 kilómetros da capital Porto Alegre, alumnos de la red pública municipal y sus familiares están desde el día 18 de mayo de 2020 participando en un proyecto que se ha realizado en alianza con las radios Princesa y Sorriso para llevar conocimientos generales y culturales a la comunidad escolar. La iniciativa pretende 
minimizar los problemas derivados de las dificultades que imponen las transmisiones realizadas a través de las redes sociales, ya que la gran mayoría de los alumnos no tienen un fácil acceso a Internet. Ahora, por medio de esa programación, tendrán acceso a diversos temas culturales y transversales, que servirán de apoyo al aprendizaje. Las clases son transmitidas los lunes y miércoles por la Rádio Sorriso y los martes y jueves las transmisiones quedan a cargo de la Rádio Princesa. Todos los programas son transmitidos de 7:30 a 7:40 (Prefeitura de Candelária, 2020).

Rádio Princesa FM 100.9 es una emisora popular, miembro de la Rede Gaúcha SAT. Su programación es musical, deportiva y de periodismo. Rádio Sorriso FM 104.3 presenta una programación ecléctica, participativa e informativa. Aporta éxitos musicales nacionales e internacionales, ya sean recientes o más antiguos.

También en Rio Grande do Sul, en la ciudad Porto Alegre, la Rádio Ipanema FM 94.9 lanzó el día 1 de junio de 2020 una serie de pequeños programas llamados Odila Educa Pelas Ondas do Rádio. El proyecto fue desarrollado en alianza con el equipo directivo del Colégio Estadual Odila Gay da Fonseca. Profesores de diversas materias olvidaron el gis junto al cuadro negro y aprendieron a utilizar el micrófono de la emisora para grabar orientaciones, consejos de estudio y resúmenes de contenidos para los alumnos que no tienen acceso a Internet. Las clases por radio son transmitidas durante la programación, todos los días, en diferentes horarios. La radio es orientada a un público joven y con un lenguaje propio, valorando la programación del rap, rock, reggae, hip-hop y música electrónica (Raddatz, 2011).

El día cinco de junio de 2020, la Secretaría de Educación de Maceió, en el Estado de Alagoas, en el Noreste de Brasil, lanzó el Projeto Rádio Escola Maceió, en alianza con el Instituto Zumbi dos Palmares y Rádio Difusora AM. Los contenidos didácticos están siendo transmitidos para los estudiantes de la red municipal de educación, a través de las ondas de radio, buscando mantener el vínculo entre las escuelas y los alumnos durante la suspensión de las clases presenciales. El contenido es elaborado y administrado por los profesores y transmitido durante la tarde. Para cada serie, están siendo destinados de 10 a 15 minutos diarios de clases por radio. Según la Secretaria 
Municipal de Educación, Ana Dayse (Prefeitura de Maceió, 2020), fueron desarrollados varios proyectos y buscado los mejores caminos para que las escuelas mantuvieran las clases y el contacto con los niños, jóvenes y adultos. Comenzaron trabajando con la computadora, el celular y las redes sociales, pero, por tener aún un número alto de alumnos sin acceso a estos recursos, buscaron en la radio, una alternativa. La Secretaría de Educación reconoce que la participación de las familias de los estudiantes es fundamental para el éxito del proyecto y que todos necesitan estar juntos para vencer este desafío (Prefeitura de Maceió, 2020). La Rádio Difusora AM 960, responsable por la transmisión de esos contenidos didácticos, es la precursora de la radio alagoana con más de 70 años de existencia y la cual, ofrece una programación variada con música, periodismo y cobertura deportiva (Ramires y Ferro, 2011).

En el Estado de Acre, al norte de Brasil, desde el día 22 de junio de 2020, los alumnos de la red estatal encontraron en dos emisoras de radio de Rio Branco un refuerzo en la transmisión de contenidos escolares, con el $20 \%$ de carga horaria remota. El otro $80 \%$ restante, será cumplido presencialmente cuando las escuelas sean autorizadas de abrir sus puertas. Los primeros casos de la enfermedad fueron registrados en la capital acreana el 17 de marzo, y ese mismo día, los 160 mil alumnos de las escuelas estatales tuvieron que abandonar sus aulas. La dinámica fue completamente transformada. Alumnos sin acceso a Internet comenzaron a recibir los contenidos didácticos no solo por medio de libros y materiales impresos que debían ser buscados en las escuelas, sino también girando el dial de la radio y sintonizando las emisoras oficiales del Estado. A través de las ondas hertzianas, niños y adolescentes, de primaria, secundaria y preparatoria, comenzaron a escuchar a sus maestros a través de un micrófono instalado en una emisora radiofónica. Por la mañana, el contenido se destina a los alumnos de primaria; por la tarde, a los estudiantes secundaria, y por la noche, a los alumnos de preparatoria. Después de la transmisión de clases, el contenido se pone a disposición en la plataforma Eduque, para aquellos que cuenten con Internet (Portal G1b, 2020).

La Rádio Aldeia FM 96.9, una de las emisoras encargadas de transmitir el contenido didáctico a los alumnos, fue inaugurada en 2003 y hoy es la matriz de una red de radios, con transmisión vía satélite y web. Es de carácter público, controlada por el gobierno del 
Estado y tiene una programación bastante ecléctica, con noticias, actividades de ocio y cultura, regionalismo, actualidad, fútbol e interactividad. Por otro lado, la Rádio Difusora Acreana AM 1400 es la más antigua del Estado. Fue fundada en 1944. También tiene un origen estatal, integrante del Sistema Público de Comunicación de Acre. Hasta inicios de la segunda década de los años 2000 la prestación de servicios fue considerada su característica principal, especialmente dirigidos al hombre de campo y a las colonias de plantaciones de caucho, habiendo ocupado el puesto de mayor medio de comunicación del Estado (Campelo, 2011).

En Oeiras, Piauí, Estado del Noroeste de Brasil, la Secretaría Municipal de Educación también encontró en la radio la forma de aproximar la escuela con los alumnos. Las clases comenzaron a ser transmitidas el día 1 de julio de 2020, por las radios Vale do Canindé y Cristo Rei FM. Según la secretaria de Educación, Tiana Tapety, las clases por radio contribuyen a fortalecer el vínculo entre la escuela y la familia durante la pandemia.

Esta nueva experiencia de utilizar la radio como comunicación para ampliar la interacción con nuestros más de seis mil alumnos nace de la necesidad de mantener el distanciamiento en función de la preservación de la vida, para evitar la contaminación por el coronavirus, y nos da una posibilidad de llegar a través de las ondas de radio. Esta herramienta que parece tan antigua pero que se renueva cada día y no pierde su espacio ante los nuevos medios, fue un aliento (Tapety, 2020).

La Rádio Cristo Rei FM es una emisora de cuño religioso, con programación educativa e informativa. Ya la Vale do Canindé AM se presenta como una emisora ecléctica.

También en dos ciudades de Rio Grande do Norte, Estado del Noroeste de Brasil, el contenido escolar de la red pública ha sido trasmitido a través de las ondas de la radio. Las ciudades de Serra Negra do Norte y Caicó tomaron la delantera con proyectos desafiantes que buscan suplir la ausencia de las nuevas tecnologías, a través de un medio de fácil acceso, incluso para las poblaciones más necesitadas. Así, el uso de la radio se ha transformado en una solución creativa en la transmisión de contenidos escolares y en la práctica de actividades. En Serra Negra do Norte, a 320 kilómetros de 
Natal, los estudiantes cuentan con un programa diario creado por la Secretaría Municipal de Educación, con clases de todas las asignaturas, de las 15 a las 16 horas. La práctica se ha considerado eficaz, a ojos de los gestores del área, y no solo los niños están aprovechando de la iniciativa (Portal UOL, 2020). Las clases remotas, transmitidas por Rádio Princesa da Serra, única emisora local, también ha atraído a muchos adultos que se dejan llevar no solo por la curiosidad, sino también por su propósito educativo. Emília Gomes tiene 20 años, vive en la zona rural de Serra Negra y, diariamente sintoniza la emisora en su pequeño radio de pila, no solo para seguir las clases de su hija de cuatro años, que comienza reconocer las letras del alfabeto, sino también para enterarse sobre otros contenidos, especialmente aquellos centrados en las ciencias, su materia favorita. Emília abandonó la escuela cuando se casó a los 16 años, y ahora, con esta nueva experiencia, ha redescubierto las ganas de volver a estudiar, y ya sueña con ello (Portal UOL, 2020). La Rádio Princesa da Serra es una emisora comunitaria que realiza transmisiones radiofónicas por la frecuencia 104.9 FM e Internet.

El uso de la radio como aula, también fue una alternativa adoptada en Caicó, a 290 kilómetros de Natal, en la región de Seridó Potiguar, con el desarrollo del programa EJA em Ação. El proyecto tiene como objetivo llegar a los alumnos del programa Educação para Jovens e Adultos y es transmitido diariamente con el debate de temas específicos para cada edición. De acuerdo con la profesora laponira Costa, quien forma parte de la Dirección Regional de Educación y Cultura, lo que se ha logrado son los denominados "círculos de cultura virtual", basados en el método Paulo Freire (Portal G1a, 2020). La intención no es hacer Educación a Distancia, sino estar más cerca de los estudiantes a partir de esa nueva metodología. La motivación del proyecto también está relacionada a la ausencia de Internet y computadoras en las casas de muchos estudiantes. Con el cierre de las escuelas, se refuerza la necesidad de buscar soluciones para no alejarlos de las aulas y una de ellas es transmitir los contenidos escolares a través de la radio. Es un proyecto que recuerda una antigua práctica de educación radiofónica existente en Caicó desde hace muchos años, el MEB, ya citado en este texto. En Caicó, los programas son transmitidos por la Rádio Rural AM 102.7. 
En Limoeiro, a 80 kilómetros de Recife, en el corazón de Pernambuco, en el Noreste brasileño, los profesores están usando las ondas de Radio Princesa do Capibaribe para administrar sus clases a los estudiantes de la red estatal. Con las escuelas a puerta cerrada, el gobierno también vio en el medio, la salida para conectar profesores y alumnos y no perjudicar aún más el año escolar de aquellos que no tienen acceso a las plataformas online. La iniciativa de llevar la escuela para los hogares de los estudiantes por medio de la radio fue la profesora de portugués Gabriella Santos. Con la ayuda de su hija Clarice, de 12 años, graba audios variados de 10 minutos y, por ello, el proyecto fue nombrado como Minuto 10. Las clases son transmitidas durante toda la programación. Para el alumno de tercer año de preparatoria, José Lyncoln Correia, que sueña con estudiar Gastronomía, las ganas de estudiar son grandes, pero las dificultades para seguir los contenidos son muchas. Él no tiene fácil acceso a Internet y poder seguir las clases por radio ayuda mucho (Portal G1c, 2020). Rádio Princesa do Capibaribe es una emisora comunitaria y está anclada en la tríada noticias, música y prestación de servicios.

Finalmente, una experiencia de la Región Sureste del país. De acuerdo con la Agencia Minas (2020), para el Régimen de Estudios No Presenciales fueron estructurados tres recursos: el Plano de Estudos Tutelados (PET); la aplicación Escola Conexão y el programa de TV Se Liga na Educação, emitido por la Rede de Televisión Minas. Además de las iniciativas del gobierno, algunas escuelas desarrollaron iniciativas propias que contemplan orientaciones para el estudio en casa, diversión, poesía, entretenimiento y afecto. El podcast EEPE_Conectando @Saberes, disponible en la plataforma Anchor.FM, es producido y realizado por profesionales de la educación en la Escola Estadual Padre Eustáquio, en Belo Horizonte. La escuela publica episodios que valoran la participación de profesores y gestores, así como de invitados y socios que dan entrevistas o interacciones lúdicas, tales como recitar poemas.

En la siguiente tabla, hemos sistematizado las 12 experiencias radiofónicas, de manera que pueda quedar claro el público objetivo, la programación y la metodología de trabajo utilizada: 
Tabla 1. Producciones radiofónicas en Brasil durante la pandemia de la Covid-19

\begin{tabular}{|c|c|c|c|c|c|c|}
\hline Fecha $^{1}$ & Estado & Ciudad & Radio & Público objetivo & Programación & Metodología \\
\hline $\begin{array}{l}\text { Desde el } 30 \\
\text { de marzo de } \\
2020\end{array}$ & Maranhão & No disponible & $\begin{array}{c}\text { Rádio } \\
\text { Timbira AM }\end{array}$ & $\begin{array}{l}\text { Alumnos de } \\
\text { primaria, } \\
\text { secundaria y } \\
\text { preparatoria }\end{array}$ & $\begin{array}{l}\text { Transmisión diaria } \\
\text { de contenidos } \\
\text { referentes a los } \\
\text { componentes } \\
\text { curriculares. }\end{array}$ & $\begin{array}{l}\text { De lunes a viernes, de } \\
16 \text { a } 18 \mathrm{hrs} \text {, toda la } \\
\text { programación de la } \\
\text { emisora está dirigida al } \\
\text { público estudiantil. Una } \\
\text { vez emitidas, estas } \\
\text { actividades } \\
\text { pedagógicas se ponen a } \\
\text { disposición en la TV y } \\
\text { en plataformas } \\
\text { virtuales como } \\
\text { YouTube, redes sociales } \\
\text { y streaming a través de } \\
\text { portales } \\
\text { gubernamentales, la } \\
\text { Secretaría de } \\
\text { Educación del Estado, } \\
\text { Rádio Timbira y la } \\
\text { Asamblea Legislativa, } \\
\text { así como emisoras } \\
\text { repetidoras del interior. }\end{array}$ \\
\hline $\begin{array}{l}\text { Final de } \\
\text { marzo de } \\
2020\end{array}$ & Ceará & Mulungu & $\begin{array}{l}\text { Rádio Paz } \\
\text { FM }\end{array}$ & $\begin{array}{l}\text { Estudiantes de } \\
\text { preparatoria de la } \\
\text { Escuela Estatal } \\
\text { Profesor Milton } \\
\text { Façanha Abreu }\end{array}$ & $\begin{array}{c}\text { Las clases se } \\
\text { dividen por áreas } \\
\text { de conocimiento, } \\
\text { como matemáticas, } \\
\text { ciencias naturales, } \\
\text { ciencias humanas, } \\
\text { idiomas y artes. Las } \\
\text { dudas relacionadas } \\
\text { a los contenidos } \\
\text { impartidos pueden } \\
\text { ser llevadas a los } \\
\text { profesores en } \\
\text { horario agendado } \\
\text { por medio de } \\
\text { Ilamadas } \\
\text { telefónicas. }\end{array}$ & $\begin{array}{l}\text { Las clases tienen } \\
\text { duración de una hora y } \\
\text { son presentadas tres } \\
\text { veces por semana por } \\
\text { los profesores de la } \\
\text { escuela. }\end{array}$ \\
\hline $\begin{array}{l}\text { Desde la } \\
\text { primera } \\
\text { semana de } \\
\text { mayo de } \\
2020\end{array}$ & Goiás & No disponible & $\begin{array}{c}\text { Radio Brasil } \\
\text { Central AM } \\
\text { y FM }\end{array}$ & $\begin{array}{c}\text { Alumnos de la red } \\
\text { estatal de } \\
\text { enseñanza. }\end{array}$ & $\begin{array}{c}\text { Clases en directo, } \\
\text { elaboradas por la } \\
\text { Secretaría de } \\
\text { Estado de } \\
\text { Educación. }\end{array}$ & $\begin{array}{c}\text { Los programas son } \\
\text { hechos dos veces al día, } \\
\text { de lunes a viernes. Por } \\
\text { la mañana de } 10 \text { a } \\
\text { 10:30, las clases son } \\
\text { destinadas a los grupos } \\
\text { de preparatoria. Ya por } \\
\text { la tarde, entre las } 15 \text { y } \\
\text { 15:30, el programa } \\
\text { aborda contenido para } \\
\text { los grupos de primaria } \\
\text { y secundaria. }\end{array}$ \\
\hline $\begin{array}{c}\text { Desde el } 18 \\
\text { de mayo de } \\
2020 \\
\end{array}$ & $\begin{array}{c}\text { Rio Grande do } \\
\text { Sul }\end{array}$ & Candelária & $\begin{array}{c}\text { Rádio } \\
\text { Princesa FM }\end{array}$ & $\begin{array}{l}\text { Alumnos de la red } \\
\text { pública municipal. }\end{array}$ & $\begin{array}{l}\text { Temas culturales y } \\
\text { transversales, de }\end{array}$ & $\begin{array}{l}\text { Las clases se } \\
\text { transmiten los lunes y } \\
\text { miércoles por la Rádio }\end{array}$ \\
\hline
\end{tabular}

${ }^{1}$ Fechas de inicio de las actividades. Las fechas de finalización no están disponibles para esta investigación ya que el período de recolección de la muestra fue de marzo a julio de 2020. 


\begin{tabular}{|c|c|c|c|c|c|c|}
\hline Fecha $^{1}$ & Estado & Ciudad & Radio & Público objetivo & Programación & Metodología \\
\hline & & & $\begin{array}{l}\text { y Rádio } \\
\text { Sorriso FM }\end{array}$ & & $\begin{array}{c}\text { apoyo al } \\
\text { aprendizaje. }\end{array}$ & $\begin{array}{c}\text { Sorriso y los martes y } \\
\text { jueves las } \\
\text { transmisiones quedan a } \\
\text { cargo de la Rádio } \\
\text { Princesa. Hora de } \\
\text { emisión: 7:30 a 7:40. }\end{array}$ \\
\hline $\begin{array}{c}\text { Desde el } 1 \\
\text { de junio de } \\
2020\end{array}$ & $\begin{array}{l}\text { Rio Grande do } \\
\text { Sul }\end{array}$ & Porto Alegre & $\begin{array}{c}\text { Rádio } \\
\text { Ipanema }\end{array}$ & $\begin{array}{l}\text { Alumnos del } \\
\text { Colégio Estadual } \\
\text { Odila Gay da } \\
\text { Fonseca. }\end{array}$ & $\begin{array}{l}\text { Serie de pequeños } \\
\text { programas } \\
\text { Ilamados Odila } \\
\text { Educa Pelas Ondas } \\
\text { do Rádio. }\end{array}$ & $\begin{array}{c}\text { Las clases por radio son } \\
\text { transmitidas durante la } \\
\text { programación, todos } \\
\text { los días, en diferentes } \\
\text { horarios. }\end{array}$ \\
\hline $\begin{array}{l}\text { Desde el } 5 \\
\text { de junio de } \\
2020\end{array}$ & Alagoas & Maceió & $\begin{array}{c}\text { Rádio } \\
\text { Difusora AM }\end{array}$ & $\begin{array}{l}\text { Estudiantes de la } \\
\text { red municipal de } \\
\text { educación. }\end{array}$ & $\begin{array}{c}\text { Contenidos } \\
\text { didácticos } \\
\text { transmitidos por la } \\
\text { radio. }\end{array}$ & $\begin{array}{c}\text { El contenido es } \\
\text { elaborado y } \\
\text { administrado por los } \\
\text { profesores y } \\
\text { transmitido durante la } \\
\text { tarde. Para cada serie } \\
\text { están siendo } \\
\text { destinados de } 10 \text { a } 15 \\
\text { minutos diarios de } \\
\text { clases por radio. }\end{array}$ \\
\hline $\begin{array}{c}\text { Desde el } 22 \\
\text { de junio de } \\
2020\end{array}$ & Acre & Rio Branco & $\begin{array}{l}\text { Rádio Aldeia } \\
\text { FM y Rádio } \\
\text { Difusora } \\
\text { Acreana AM }\end{array}$ & $\begin{array}{l}\text { Alumnos de la red } \\
\text { pública estatal. }\end{array}$ & $\begin{array}{l}\text { Transmisión de } \\
\text { contenidos } \\
\text { escolares, con el } \\
20 \% \text { de carga } \\
\text { horaria remota. El } \\
\text { otro } 80 \% \text { restante, } \\
\text { será cumplido } \\
\text { presencialmente } \\
\text { cuando las escuelas } \\
\text { sean autorizadas de } \\
\text { abrir sus puertas. }\end{array}$ & $\begin{array}{c}\text { Por la mañana, el } \\
\text { contenido se destina a } \\
\text { los alumnos de } \\
\text { primaria; por la tarde, a } \\
\text { los estudiantes } \\
\text { secundaria, y por la } \\
\text { noche, a los alumnos } \\
\text { de preparatoria. } \\
\text { Después de la } \\
\text { transmisión de clases, } \\
\text { el contenido se pone a } \\
\text { disposición en la } \\
\text { plataforma Eduque, } \\
\text { para aquellos que } \\
\text { cuenten con internet. }\end{array}$ \\
\hline $\begin{array}{l}\text { Desde el } 1 \\
\text { de julio de } \\
2020\end{array}$ & Piauí & Oeiras & $\begin{array}{c}\text { Rádio Cristo } \\
\text { Rei FM y } \\
\text { Rádio Vale } \\
\text { do Canindé } \\
\text { AM }\end{array}$ & $\begin{array}{c}\text { Seis mil alumnos } \\
\text { de la red pública } \\
\text { municipal. }\end{array}$ & Clases por radio. & $\begin{array}{l}\text { Clases como forma } \\
\text { para ampliar la } \\
\text { interacción con los } \\
\text { alumnos. }\end{array}$ \\
\hline \multirow[t]{2}{*}{$\begin{array}{l}\text { Fecha no } \\
\text { disponible }\end{array}$} & $\begin{array}{l}\text { Rio Grande do } \\
\text { Norte }\end{array}$ & $\begin{array}{l}\text { Serra Negra } \\
\text { do Norte }\end{array}$ & $\begin{array}{l}\text { Rádio } \\
\text { Princesa da } \\
\text { Serra FM }\end{array}$ & $\begin{array}{l}\text { Alumnos de la red } \\
\text { pública municipal. }\end{array}$ & $\begin{array}{l}\text { Programa diario } \\
\text { creado por la } \\
\text { Secretaría } \\
\text { Municipal de } \\
\text { Educación, con } \\
\text { clases de todas las } \\
\text { materias, de las } 15 \\
\text { a las } 16 \text { horas. }\end{array}$ & $\begin{array}{c}\text { Transmisión de } \\
\text { contenidos escolares y } \\
\text { práctica de actividades. }\end{array}$ \\
\hline & & Caicó & $\begin{array}{l}\text { Rádio Rural } \\
\text { AM }\end{array}$ & $\begin{array}{l}\text { El proyecto tiene } \\
\text { como objetivo } \\
\text { llegar a los } \\
\text { alumnos del } \\
\text { programa } \\
\text { Educação para } \\
\text { Jovens e Adultos. }\end{array}$ & $\begin{array}{l}\text { Programa EJA em } \\
\text { Ação. }\end{array}$ & $\begin{array}{c}\text { Es transmitido } \\
\text { diariamente con el } \\
\text { debate de temas } \\
\text { específicos para cada } \\
\text { edición. }\end{array}$ \\
\hline
\end{tabular}




\begin{tabular}{|c|c|c|c|c|c|c|}
\hline Fecha $^{1}$ & Estado & Ciudad & Radio & Público objetivo & Programación & Metodología \\
\hline $\begin{array}{l}\text { Fecha no } \\
\text { disponible }\end{array}$ & Pernambuco & Limoeiro & $\begin{array}{c}\text { Radio } \\
\text { Princesa do } \\
\text { Capibaribe } \\
\text { FM }\end{array}$ & $\begin{array}{l}\text { Estudiantes de la } \\
\text { red estatal. }\end{array}$ & $\begin{array}{l}\text { Audios variados de } \\
10 \text { minutos } \\
\text { nombrados como } \\
\text { Minuto } 10 .\end{array}$ & $\begin{array}{l}\text { Las clases son } \\
\text { transmitidas durante } \\
\text { toda la programación. }\end{array}$ \\
\hline $\begin{array}{l}\text { Fecha no } \\
\text { disponible }\end{array}$ & Minas Gerais & $\begin{array}{c}\text { Belo } \\
\text { Horizonte }\end{array}$ & $\begin{array}{l}\text { Plataforma } \\
\text { Anchor.FM }\end{array}$ & $\begin{array}{l}\text { Alumnos de la } \\
\text { Escola Estadual } \\
\text { Padre Eustáquio. }\end{array}$ & $\begin{array}{l}\text { Producción del } \\
\text { podcast } \\
\text { EEPE_Conectando } \\
\text { @Saberes. }\end{array}$ & $\begin{array}{l}\text { La escuela, publica } \\
\text { episodios que valoran } \\
\text { la participación de } \\
\text { profesores y gestores, } \\
\text { así como de invitados y } \\
\text { socios que dan } \\
\text { entrevistas o } \\
\text { interacciones lúdicas, } \\
\text { tales como recitar } \\
\text { poemas. }\end{array}$ \\
\hline
\end{tabular}

Fuente: Datos de la investigación

Los casos de la muestra señalan algunos caminos de este vínculo entre la radio y la educación en Brasil durante la pandemia:

1. Fechas: marzo a julio de 2020.

2. Estados involucrados: 10 (Acre, Alagoas, Ceará, Goiás, Maranhão, Minas Gerais, Pernambuco, Piauí, Rio Grande do Norte y Rio Grande do Sul).

3. Ciudades involucradas: 10 (Belo Horizonte, Caicó, Candelária, Limoeiro, Maceió, Mulungu, Oeiras, Porto Alegre, Rio Branco y Serra Negra do Norte).

4. Emisoras de radio involucradas: Plataforma Anchor.FM y 15 emissoras (Rádio Aldeia FM, Rádio Cristo Rei FM, Rádio Difusora Acreana AM, Rádio Difusora AM, Rádio Ipanema, Rádio Paz FM, Rádio Princesa da Serra FM, Radio Princesa do Capibaribe FM, Rádio Princesa FM, Rádio Rural AM, Rádio Sorriso FM, Rádio Timbira AM, Rádio Vale do Canindé AM y Radios Brasil Central AM y FM).

5. Público objetivo: alumnos de escuelas públicas, tanto niños como jóvenes y adultos.

6. Programación: clases en directo, con transmisión de contenidos escolares o transversales, así como programas grabados previamente a la transmisión.

7. Metodología: clases con frecuencia y duración variada. 
Luego de relevar estas experiencias, podemos entender este movimiento de la radio brasileña, nacido de forma emergente durante la pandemia, como un instrumento de educación, que como lo señala Kaplún (1978): fue realizada la producción de una programación que tiende a estimular a los oyentes; se integra a la realidad de los alumnos, partiendo de una problemática concreta, de su situación vivencial; tras elementos para comprender y problematizar esa realidad; se identifica con las necesidades y los intereses de la comunidad popular a la que se dirige; estimula el diálogo y la participación; acentúa los valores comunitarios y solidarios, llevarán a la unión y a la cooperación; estimula el desarrollo de la conciencia crítica frente a la pandemia y colabora a que el oyente tome conciencia de la propia dignidad, del propio valor como persona.

\section{CONCLUSIÓN}

Además de la labor de información y entretenimiento, la radio desempeña un papel primordial en la educación, siendo una herramienta de movilización de la sociedad en la que la ciudadanía es uno de los elementos articuladores. En Brasil, durante la pandemia, podemos entender la radio como un actor social que refuerza su función política en la articulación pedagógica que, en tiempos de aislamiento social, necesita ir más allá del aula física, ganando espacios como el Internet. Sin embargo, la falta de disponibilidad de conexiones de red en algunos lugares, desplaza a la radio del papel de emisor de contenido educativo para un locus posible para mantener la interacción con la comunidad escolar a través de estrategias pedagógicas que retoman la asociación tradicional entre radio y educación.

Es interesante observar que incluso en una sociedad conectada y multiplataforma, ante epidemias, catástrofes y grandes calamidades, la radio es (re)convocada a un papel protagónico, dadas sus características de dispositivo simple, barato y accesible; forma de transmisión ya secular e intensa capilaridad, llegando a lugares donde no es posible pensar en Internet.

Le corresponde a la radio permanecer en su rol de conectar a las personas, promover la interacción, llevar la noticia, aclarar rumores y verificar datos, garantizándole a la 
sociedad el derecho a la información. Depende de la radio, sin embargo, la presencia educativa en la ausencia de aulas presenciales y la precariedad de redes de conexión, que crean abismos insuperables. En Brasil, frente a las barreras, los gobiernos estatales y municipales han convocado a la radio para abordar las dificultades impuestas en establecer un canal para conectar la escuela y los alumnos.

\section{REFERENCIAS BIBLIOGRÁFICAS}

Abert (2019). Rádio - aliado da comunidade em situações de emergência.Recuperado de https://cutt.ly/aR1UNgU

Agência Minas (2020). Secretária de Educação detalha Regime de Estudo não Presencial na rede estadual de ensino. Recuperado de https://cutt.ly/FR1AhW1

Albertin, D. O. (2016). Educação pelo tempo do rádio: desafios e perspectivas. Tese de Doutorado - Programa de Pós-Graduação em Educação. Universidade Nove de Julho. São Paulo. Recuperado de https://cutt.ly/uR1URnv

Anchor.FM (2020).EEPE_Conectando@Saberes. Recuperado de https://cutt.ly/GR1UUOs

Aula de longe, mas ao pé do ouvido. Portal UOL (2020). Recuperado de https://cutt.ly/hR1UZ1e

Aulas de escolas municipais de Candelária acontecerão via rádio a partir de segundafeira. Prefeitura de Candelária (2020). Recuperado de https://cutt.ly/cn9tmnB

Campelo, W. (2001). Das ondas do rádio à tela da TV - o som e a imagem na cidade das Alterosas (1900-1950). Dissertação de Mestrado. Universidade São Marcos. São Paulo.

Campelo, W. (2011). Panorama do rádio em Rio Branco. En N. Prata (Org.). Panorama do Rádio no Brasil. Florianópolis: Insular.

Campos, A. y Caetano, M. M. R. (2011). Panorama do rádio em Goiânia. En N. Prata (Org.). Panorama do Rádio no Brasil. Florianópolis: Insular. 
Cidades do interior do RN transmitem conteúdo escolar através do rádio para estudantes da rede pública. Portal G1a (2020). Recuperado de https://cutt.ly/MR1IzUy

Citelli, A. (2019). Comunicação e educação: a linguagem em movimento. São Paulo: Senac.

Correio dos Municípios (2020). Secretária lança projeto que vai levar aulas via rádio a alunos da rede. Prefeitura de Maceió (2020). Recuperado de https://cutt.ly/PR1AQsK Diário do Nordeste (2020). Professores de escola em Mulungu usam rádio comunitária para dar aulas aos alunos sem internet. Recuperado de https://cutt.ly/ER1PEWF

Hines, M. apud Strauss, V. (2020). In Chicago, schools closed during a 1937 polio epidemic and kids learned from home - over the radio. The Washington Post. Recuperado de https://cutt.ly/HR1/7a1

IBGE (2019). Pesquisa Nacional por Amostra de Domicílios. Recuperado de https://cutt.ly/OR1OoK2

Kantar Ibope Media (2019). Inside Radio 2019. Recuperado de https://cutt.ly/7R1OQEi Kaplún, M. (1978). Producción de Programas de Radio. El guión - la realización. México: Editorial Cromocolor.

Martínez-Costa, M. P. y Prata, N. (2017). La radio en busca de su audiencia: hacia una escucha diversificada y multiplataforma. Intercom - Revista Brasileira de Ciências da Comunicação, 40(3), 109-128. Recuperado de https://cutt.ly/RR1Pi9n

Pimentel, F. P. (2009). O rádio educativo no Brasil - Uma visão histórica. Rio de Janeiro: Soarmec.

Portal Amazônia (2020). Maranhão também veiculará aulas do ensino fundamental e médio pela televisão e rádio. Recuperado de https://cutt.ly/tR1OZtV

Portal G1b (2020). Com 20\% de carga horária remota, Educação vai transmitir aulas pela TV e rádio para alunos no AC. Recuperado de https://cutt.ly/sR1IXYe 
Portal G1c (2020). Professores adaptam aulas para o rádio para ajudar estudantes que não têm acesso à internet. Recuperado de https://cutt.ly/aR1Pj1a

Raddatz, V. L. S. (2011). Panorama do rádio em Porto Alegre. En N. Prata (Org.). Panorama do Rádio no Brasil. Florianópolis: Insular.

Ramires, L. y Ferro, R. J. O. (2011). Panorama do rádio em Maceió. En N. Prata (Org.). Panorama do Rádio no Brasil. Florianópolis: Insular.

Ribeiro, L. A. y Praxedes, L. A. (2011). Panorama do rádio em São Luís. En N. Prata (Org.). Panorama do Rádio no Brasil. Florianópolis: Insular.

Santaella, L. (2000). A cultura das mídias. São Paulo: Experimento.

Secretaria de Estado da Educação (2020). Rede estadual de ensino transmite aulas pela TV a partir de segunda-feira. Recuperado de https://cutt.ly/aR1P1y1

Soares, I. (1999). Comunicação-educação: a emergência de um novo campo e o perfil dos seus profissionais. Revista Contato, 1(2).

Tapety, T. (2020). Oeiras usa o rádio como estratégia de ensino durante a pandemia. Recuperado de https://cutt.ly/dR1A4Yh

The New York Times (2021). 'No estoy aprendiendo nada': América Latina enfrenta una crisis de educación pandémica. Recuperado de https://cutt.ly/hR1A5Ft

Unicef (2020). Covid-19: mais de $97 \%$ dos estudantes ainda estão fora das salas de aula na América Latina e no Caribe. Recuperado de https://cutt.ly/xR1SyLb 